\title{
Continuity of information in cancer care: evaluation of a logbook
}

\author{
A. van Wersch ${ }^{\mathrm{a}, *}$, M.F. de Boer ${ }^{\mathrm{b}}$, E. van der Does ${ }^{\mathrm{c}}$, P. de Jong ${ }^{\mathrm{d}}$, P. Knegt ${ }^{\mathrm{e}}$, \\ C.A. Mccuwis ${ }^{\mathrm{b}}$, P. Stringer, J.F.A. Pruyn ${ }^{\mathrm{a}}$ \\ ${ }^{a}$ Institute of Health and Environmental Issues, Willemstad, The Netherlands \\ ${ }^{\mathrm{b}}$ Academic Hospital Rotterdam. Daniel den Hoed Clinic, Rotterdam, The Netherlands \\ "Institute for the General Practice of Family Medicine, Rotterdam, The Netherlands \\ ${ }^{\mathrm{D}}$ Dutch Society for Laryngectomees, Rotterdam, The Netherlands \\ 'Academic Hospital Rotterdam, Dijkzigt, Rotterdam, The Nethelands
}

Received 7 September 1996; revised 1 March 1997; accepted 9 March 1997

\begin{abstract}
A logbook, or patient-dossier, was developed, to improve continuity of information in the treatment and care of head-and-neck cancer patients. It contained information modules on different aspects of care, as well as forms to facilitate communication both between patient and care-professional and between the various care-professionals. The logbook's effectiveness was evaluated in two hospitals in Rotterdam, by comparing outcomes for trial and comparison groups of, respectively, 71 and 54 patients and 59 and 35 care-professionals. Trial patients proved to be better informed, to receive more support and to experience fewer psychosocial problems. Professionals who used the logbook were better informed about their patients, and about the care-activities of fellow-professionals than those who did not. They recognised an improvement in their contact with colleagues and in the harmonisation of their respective care-activities. (C) 1997 Elsevier Science Ireland Ltd.
\end{abstract}

Keywords: Continuity of information; Head-and-neck cancer; Logbook; Care-professional communication

\section{Introduction}

As many as twenty different disciplines may be involved in the diagnosis, treatment and care of head-and-neck cancer patients. A study carried out in the Netherlands among family doctors, community nurses, home-helps and other professionals who have

\footnotetext{
*Corresponding author. Present address: University of Teesside, Department of Psychology, School of Social Sciences, Middlesbrough, Cleveland TS1 3BA, UK.
}

contact with these patients has revealed that its organisation is complex and often chaotic [1]. Communication between the different disciplines is generally poor. In a study of 133 patients being treated for head-and-neck cancer, nearly one in four $(23 \%)$ reported receiving poor information from the hospital about possibilities for their care and counselling following discharge [2]. Moreover, $73 \%$ had received little or no significant information, and $59 \%$ little or no support, from their family doctor.

Patients being treated for head-and-neck tumours 
are often confronted with major psychosocial problems [3] - not only because of their fear of the disease and uncertainty about survival, but also because of the frequently invasive and mutilating treatment, which can give them difficulties in speech, eating and swallowing, as well as problems with their appearance. They appear to need extra support to help them cope with psychological, as well as physical, problems [4]. Open discussion of the disease in the family, social support and perceptions of having obtained adequate information from the specialist have been found to be the most important predictors of positive rehabilitation outcomes in the 2-6 year post-treatment period [3]. Nevertheless, the (after-)care of these patients leaves much to be desired [5]. One important cause of shortcomings is unfamiliarity on the part of the various care-professionals, especially in primary care, with this kind of patient and the problems which they may experience.

The amount of information which should be imparted to the cancer-patient has been a widelydiscussed issue. Fallowfield and colleagues [6-8] found that doctors often underestimate the amount and type of information which cancer patients require, and may only give information to those who actively seek it. Patients seem not always to wish to receive all the information which is available [9]. When they receive it, they may not recall it [10]. At the same time, patients are unhappy with the amount of information which they are given and about the opportunities for discussion of their diagnosis and treatment options. A (perceived) lack of information may be associated with measurable post-treatment uncertainty, anxiety and depression [11-16].

The situation may be aggravated by poor communication between primary and secondary careprofessionals [17]. Van der Wouden [18] reported a lack of formal arrangements in the relation between surgeons and family doctors. Any information exchanged was generally in writing and poorly-attuned to the other party's needs, and it reached the family doctor too late. One-half of the 113 care-professionals (doctors, nurses, laboratory staff and psychosocial counsellors) whom Visser and Menko [19] interviewed, in 16 out-patient departments at six hospitals, indicated that they had experienced problems in the relation between primary and secondary carers of cancer patients. They ascribed the problems, above all, to a lack of knowledge among primary carers about the disease, radiation, and consequences of treatment - and to difficulties which secondary carers had in contacting primary carers. In the study by van der Horst et al. [20], it appeared that careprofessionals (including family doctors and community nurses) had little contact with one another, and agreed to only a limited extent about the healthstatus and functioning of their patients. For example, only $20 \%$ of family doctors knew whether a community nurse was involved in the care of a particular cancer patient. Even fewer professionals knew whether others (eg. a physiotherapist, social worker) were involved. In a study of cancer patients and their various carers, Courtens and Crebolder [21] found that carers rarely agreed about their respective tasks in giving information and counselling to patients.

On the basis of the literature referred to above, it is assumed that head-and-neck cancer patients could profit - particularly with regard to their psychosocial problems - from receiving a greater 'continuity of information' than hitherto.

'Continuity of information' encompasses three aspects of the information which patients might receive. It refers to information which:

(i) provides patients with a 'scenario' of the whole course of their diagnosis, treatment and (after-) care - i.e. comprehensive and structured information;

(ii) ensures consistency between the different contributing disciplines - i.e. is co-ordinated information; and

(iii) covers several possible functions of information, namely: 'pure' information, instruction, education and guidance/counselling [22].

Thus, 'continuous information' includes not only information about the disease and its treatment, and instruction on, for example, looking after the wound and drain; but also some stimulation of independence and self-reliance in patients [23], and explicit attention to their psychosocial and emotional guidance and counselling $[7,12,13,24,25]$.

Not only should patients themselves benefit from such 'continuity of information', but it should also enable care-professionals to become more widely informed about a patient, to communicate more 
effectively with other care-professionals, and to harmonise and improve their respective care-activities with regard to particular patients.

One means of achieving 'continuity of information' may be by way of a 'logbook' or patientdossier, as suggested by Courtens and Crebolder [21].

\section{Origin and aim of the study}

The study reported here was initiated by the Rotterdam Head-and-Neck Tumour Foundation, the Dutch Society for Laryngectomees and the Institute for Health and Environmental Issues, under the leadership of the second author.

It set out to develop, implement and evaluate a logbook for the care and treatment of head-and-neck cancer patients. Broad questions to be examined were, for example: Is patients' use of the logbook associated with their having fewer psychosocial problems? Does it help them gain a better grasp of their situation? Do care-professionals perceive an improvement in their communication with patients and other professionals as a result of use of the logbook?

More specifically, it was expected that use of the logbook, as a new means of communication with and between care-professionals, would lead to an increased continuity of information and be associated with:

\section{1. patients}

(a) receiving more, clearer and less contradictory information - in particular, about the possibilities for care following discharge,

(b) feeling less uncertain,

(c) receiving more support,

(d) experiencing fewer psychosocial problems anxiety, depression, fear, insomnia, loneliness and tension.

2. and professionals

(a) having more information available about a patient's disease, treatment and psychosocial situation,

(b) achieving better contact with patients,

(c) harmonising their care-activities (adjusting them to one another's).

\section{Logbook}

In the present study, a logbook is defined as an instrument not only for giving, but also for exchanging information. It contains both a 'communication' and an 'information' section, in a loose-leaf bound format.

The logbook is the property of the patient, who may ultimately decide who has access to its contents. It stays with the patient, but is intended to be available at all consultations.

Subject to the patient's wishes, any care-professional (and, in the domestic context, any home-help, voluntary worker or informal carer) may consult the logbook; and, in particular, make their own notes in the communication section on any aspect of treatment, nursing, other care or counselling. Similarly, patients can use the logbook to record their observations, experiences, feelings and conclusions. Their record may assist professionals in harmonising their care-activities to the expressed needs of the individual patient.

A logbook is intended to make clear to all parties (patient and professionals) who has said and done what and when. Information given by one professional is available for all others to read - thus anticipating the possibility of different professionals having to rely on the patients themselves for details of their treatment. There should also be less likelihood that a patient receives (apparently) contradictory information from different sources.

\subsection{Development of the logbook for head-and- neck cancer patients}

University hospitals, integrated cancer centres and other organisations in the Netherlands were asked to supply existing examples of logbooks or of similar materials. This step was supplemented by a literature search for studies using a logbook approach and by drawing together any informational material which was available specifically for head-and-neck patients [26].

In addition, interviews were conducted with a number of (previous) patients and care-professionals (ENT-physicians, radiotherapists, family doctors, brachytherapists, prothesiologists, dentists, dental assistants, speech therapists, physiotherapists, nurs- 
ing staff, social nurses and dieticians), to determine both what sort of information about the disease they normally received or offered, and their reactions to the logbook concept and its use.

On the basis of the materials collected, a first draft of the logbook was drawn up, and piloted with ten patients. All drafts of the logbook (as well as all aspects of its subsequent implementation) were discussed by a supervisory group, consisting of ENTphysicians and specialists in patient-information, social nursing, psychosocial care and home-nursing, as well as a social oncologist and the study coordinator. The major change as a result of this preliminary work was the inclusion of a pull-out folder containing the forms in the communication section (see below). This folder was less bulky than the rest of the logbook, which also included a quite extensive information section and subsidiary material, and was less cumbersome to take to consultations.

\subsection{Logbook content}

The communication section consisted of seven forms. It was intended to promote communication between care-professionals and patient, and between professionals themselves. It enabled the professionals to gain a rapid and comprehensive overview of a patient's problems and of the treatment or other procedures applied to date. The communication forms recorded: (i) various patient details, including telephone numbers of their care-professionals and other contact persons, and such details as allergy and tendency to bleed; (ii) general and oncological casehistories; (iii) medication; (iv) the medical, paramedical and psychosocial situation at discharge; (v) a psychosocial profile (including living situation, household composition, available social support); (vi) an 'interchange' form on which both the patient and carers could record questions, sources of uncertainty, dissatisfactions and other comments; and (vii) a form on which the patient could note down his or her thoughts and conclusions.

The information section of the logbook consisted of 14 modules. Written information, illustrated with drawings and pictures, was presented in a uniform format and style for the following topics: (i) What is cancer? (ii) Social nursing; (iii) Diet; (iv) Treatment; (v) Speech therapy; (vi) Physiotherapy; (vii) Care of the canula and stoma; (viii) Radiotherapy in general; (ix) Brachytherapy; (x) Dentistry; (xi) Prothesiology; (xii) Home-care (family. doctor and community nurse); (xiii) Contact with an association for fellowsufferers; and (xiv) Coping.

Subsidiary sections of the logbook contained a list of contents, advice on its use, a glossary of terms, and. details of other available information-folders and -booklets.

\subsection{Implementation}

Head-and-neck cancer patients at two locations of the Academic Hospital Rotterdam (Dr. Daniel den Hoed Cancer Clinic and Dijkzigt Hospital), who fell into one of four treatment categories (see below), were treated in accordance with the same protocol; with the exception that patients at the former location were offered the logbook (trial group), while patients at the latter were not offered it (comparison group).

During the period May 1994 to April 1995, 110 patients were identified who fitted the criteria for the trial group. For a variety of reasons, 26 of them did not receive a logbook. These reasons included dementia and insufficient command of the Dutch language. Only 3 patients actually refused to take the logbook. Of the 84 who received a logbook, 4 declined at some point to continue using it and a further 9 died before the evaluation phase of the study. The logbook was offered to trial group patients by their ENT-physician, immediately after their receipt of the 'bad news' that they had a tumour which needed treatment. All patients received full information about the trial and an informed consent form (approved by the Medical-Ethical Committee of the hospital).

The first three and last three modules of the information section were standard items in the logbook of all patients. Other modules were variously included for the four treatment categories of patient. These other modules were distributed and introduced by care-professionals at the time of first treatment: variously by EN'I'-physicians, radiotherapists, nurses, speech therapists, physiotherapists, prothesiologists, dentists, dental assistants, radiotherapy information-officers, and brachytherapists.

Before the trial began, the logbook was introduced 
both in writing and orally to all the staff (including secretarial) involved, and their various roles in the trial were explained. In addition to making sure and recording that the modules relevant to their care were placed in the logbook and and explained to patients, these roles included the distribution of additional informational material, keeping up-to-date with and responding to the communication section of their patient's logbook, making entries in the logbook's forms, and keeping records of the trial's progress.

The social nurse acted as 'logbook coordinator'. She took care of patients after their 'bad news' consultation; explained the aim, function and use of the logbook and ensured that each patient had all the relevant modules; entered treatment details and completed the psychosocial profile; made sure that the discharge form was completed; and notified family doctors by telephone and in writing that one of their patients had been given the logbook, and asked them for their collaboration in its use.

\section{Methods}

\subsection{Patients}

Evaluation of the logbook in use was carried out primarily by means of questionnaires administered to both trial and comparison groups of patients and to professionals involved in their care. In addition, the logbook itself was evaluated by means of a checklist, which was completed by the co-ordinator of the project and a social nurse.

An evaluation questionnairc was sent to the 71 surviving patients who had agreed to use the logbook, and to 54 comparison patients who agreed to fill in the questionnaire in the Dijkzigt Hospital. All patients had been treated during the same period.

Patients fell into one of four categories, according to the treatment which they received:

1. Laryngectomy involving the surgical removal of the larynx - the standard operative procedure for patients with a carcinoma of the larynx or hypopharynx

2. Commando for patients with a carcinoma of the mouth or pharynx - a radical form of surgery, with or without subsequent treatment by radiation
3. Facial a treatment involving facial mutilation, as a result of which internal and external prostheses were necessary

4. Radiation for patients who underwent intensive radiation treatment for a tumour in the head-andneck area, and as a consequence suffered particular speech and ingestion problems.

\subsection{Patients' questionnaire}

The patients' questionnaire dealt with:

(i) classificatory variables; perception of the nature and quality of the different types of information and social support which they received from various care-professionals and others; (ii) psychosocial variables. As a basis for measuring the psychosocial variables, a theoretical model of coping with cancer was used [25]. The model is based on the assumption that uncertainty, negative feelings (tension, fear, anxiety, depression, loneliness and insomnia), loss of control and threatened self-esteem are the most important psychosocial problems experienced by cancer patients. Scales from van den Borne and Pruyn's research were used to measure these outcomes $[28,29]$.

(iii) use of, and reactions to, both sections of the logbook and the logbook as a whole.

Part (iii) of this questionnaire was administered only to the trial group.

\subsection{Questionnaire for care-professionals}

The questionnaire for care-professionals contained questions about:

(i) their experience of caring for head-and neck cancer patients, normal attitudes to informationgiving practices

(ii) their own use of and reaction to the logbook, their ideas and suggestions for its modification.

Part (ii) of this questionnaire was administered only to professionals who cared for patients in the trial group.

All constucts were measured by multiple items. A 
variety of open and closed questions, dichotomous response categories and scales was used in the questionnaires - a copy of which may be obtained from the second author.

\subsection{Checklist}

A 23-item checklist was used to examine the logbook itself - in particular, whether details in the various communication forms were filled in, and how comprehensively they were filled in. The checklist was completed 12 months after the initial implementation of the logbook, by social nursing staff and the study co-ordinator.

\section{Results}

\subsection{Patients}

Evaluation questionnaires were returned by $84 \%$ of the patients who had participated in the logbook trial; and by $72 \%$ of patients in the comparison group (Table 1). Most patients of both groups were male (trial: $80 \%$; comparison $70 \%$ ) and lived together with another person (trial 75\%; comparison: 60\%). The average age of both groups was in the early sixties (trial group: 61 years, SD 11 years, min. 37 years, max. 85 years; comparison group: 64 years, SD 12 years, min. 35 years, max. 92 years).

\subsubsection{Use of the logbook}

Ninety-one percent of the 60 trial patients who completed the evaluation questionnaire had read the

Table 1

Numbers of patient questionnaires distributed (D) and returned (R)

\begin{tabular}{lccccr}
\hline Treatment mode & \multicolumn{2}{c}{ Trial group } & & \multicolumn{2}{l}{$\begin{array}{l}\text { Comparison } \\
\text { group }\end{array}$} \\
\cline { 2 - 3 } \cline { 6 - 6 } & $\mathrm{D}$ & $\mathrm{R}$ & & $\mathrm{D}$ & $\mathrm{R}$ \\
\hline Commando & 37 & 30 & & 25 & 17 \\
Laryngectomy & 23 & 21 & & 12 & 10 \\
Radiation & 7 & 5 & & 14 & 10 \\
Face & 4 & 4 & 3 & 2 \\
Total & 71 & 60 & & 54 & 39 \\
Response rate & $84 \%$ & & & $72 \%$ & \\
\hline
\end{tabular}

logbook in its entirety; and those closest to the patient had read it in $91 \%$ of cases. Ninety-four percent of patients had given the logbook to a careprofessional to read - in particular, to their family doctor (78\%), ENT-physician (70\%), and/or nursing staff $(67 \%)$.

Forty-seven percent reported that they had made entries in the logbook: $36 \%$ on the patient's notes form and $29 \%$ on the interchange form. The most frequent entries were descriptions of experiences (by $32 \%$ of patients) and questions for care-professionals (by 24\%). Patients had various reasons for not having made an entry: in particular, $27 \%$ had no questions, $21 \%$ did not like writing, and $21 \%$ thought that their feelings and experiences were not the concern of other people. Most of the patients who had used the patient's notes form used it as a diary.

The checklist showed that most of the communication forms were filled in by the care-professionals. Patients had recorded comments in 12 cases (on average, four comments), family-members in 15 cases (on average, three comments) and a fellowsufferer in only one case (with eight comments).

The most frequently read and valued information modules were those on 'What is cancer?', 'Treatment' and 'Social nursing'. The glossary and list of addresses was hardly ever or never used by one-half of the patients; and the form which listed careprofessionals' contact-numbers was used by only $12 \%$ of patients, each in just one instance.

\subsubsection{Reactions to the logbook}

The great majority of patients $(88 \%)$ indicated that the logbook had clarified a good deal about their treatment. Almost as many found that it was not difficult to read and that it did not provide too much information all at once.

A majority was satisfied with the information modules. They were found to be clear and wellorganised (by $100 \%$ of patients), comprehensive $(92 \%)$, not too difficult $(84 \%)$, neither too brief $(82 \%)$ nor too long $(78 \%)$.

Most patients (93\%) found the logbook sufficiently comprehensive, experienced no disadvantages from using it (98\%) and had no suggestions for its improvement $(92 \%)$. (The three suggestions which were made were of an organisational nature, and did 
not have to do with the form or content of the logbook.)

\subsubsection{Psychosocial functioning}

\subsubsection{Information and uncertainty}

First, it should be noted that one-half $(51 \%)$ of the comparison patients had been given no written information about their disease or its treatment. For the other half, no formal arrangements could be detected which would make it possible for them to anticipate what material might be provided to them, when or by whom.

Some consequences of this absence of (formal arrangements for) any provision of information can be seen in a number of significant differences between the responses of trial and comparison patients (Table 2). More of the trial than the comparison patients found that they had received sufficient and clear information about their disease and its treatment. This difference was particularly noticable with regard to the perceived clarity of information which they received from a social nurse or social worker, other nursing staff and the ENT-physician; but not with regard to that from the family doctor or a fellow-sufferer. More than one-half of the comparison patients indicated a need for more information about their disease and its treatment, as against $17 \%$ of the trial group.

Only one in five of the trial group considered that they had received insufficient information in hospital about the possibilities for supervision and care following discharge, as opposed to nearly one-half of the comparison group. Many more of the latter group had a need for information about how to solve particular problems and about where they could obtain help. Five times as many of them reported that they had received contradictory information from different care-professionals.

Fewer of the patients who had received the logbook suffered from uncertainty about what tests they should expect, how the operation would proceed, and how they could use exercises and/or a diet to stay fit. Sixty-four percent of them indicated quite explicitly that they thought that without the logbook they would have felt more uncertain than in fact they did.

\subsubsection{Support}

More patients in the trial group reported receiving support and fewer experienced negative feelings. More than half of them $(52 \%)$ indicated that the logbook had served as a support when they were feeling miserable, and $49 \%$ thought that they had received more support from care-professionals as a result of the logbook. For $81 \%$, the logbook made it easier to talk about their disease to those closest to them; and it helped $77 \%$ to find where they might go with their questions or problems.

The support from the various care-professionals which patients reported did not differ significantly between the two groups - in the cases, that is, of

Table 2

Numbers of care-professional questionnaires distributed (D) and returned (R)

\begin{tabular}{|c|c|c|c|c|}
\hline & \multicolumn{2}{|c|}{ Trial group } & \multicolumn{2}{|c|}{ Comparison group } \\
\hline & $\mathrm{D}$ & $\mathrm{R}$ & $\mathrm{D}$ & $\mathbf{R}$ \\
\hline Family doctors & 68 & 25 & 52 & 18 \\
\hline Nursing staff & 17 & 15 & 17 & 11 \\
\hline $\begin{array}{l}\text { Paramedics (physiotherapy, speech } \\
\text { therapy, brachytherapy, }\end{array}$ & & & & \\
\hline $\begin{array}{l}\text { dental assistants, prothesiology, } \\
\text { social nursing/social work, } \\
\text { information officer radiotherapy) } \\
\text { Specialists (ENT, internal medicine, } \\
\text { radiotherapy, oral surgery/ }\end{array}$ & 12 & 11 & 6 & 4 \\
\hline dentistry) & 8 & 8 & 3 & 2 \\
\hline Total & 105 & 59 & 78 & 35 \\
\hline Response rate & $54 \%$ & & $45 \%$ & \\
\hline
\end{tabular}


the family doctor, ENT-physician and nursing staff. Nor was there a difference in the cases of partner, children and fellow-sufferers. However, four times as many of trial as comparison patients did report having received significant support from a social nurse or social worker in coping with possible tensions or problems (Table 3 ).

Seventy-eight percent of logbook patients found that it improved their grasp of their situation. That the logbook assisted in the harmonising of care of patients' individual needs was apparent from their expressed satisfaction with the answers which they received to their questions: many fewer of the trial group were dissatisfied (Table 4).

\subsubsection{Psychosocial problems}

The psychosocial problems which patients experienced differed significantly between the two groups. However, only item-differences were found in the scales from van den Borne and Pruyn's

Table 3

Significant differences between trial and comparison groups on information and uncertainty variables

\begin{tabular}{|c|c|c|c|}
\hline & Trial (\%) & Comparison $(\%)$ & $p\left(\chi^{2}\right)$ \\
\hline \multicolumn{4}{|c|}{ More (and simpler) information received, or not } \\
\hline Clear written information & 67 & 33 & .005 \\
\hline Sufficient written information & 78 & 39 & .001 \\
\hline Clear information from ENT doctor & 93 & 78 & .05 \\
\hline from nursing staff & 69 & 41 & .05 \\
\hline from social nurses/social workers & 72 & 22 & .001 \\
\hline \multicolumn{4}{|c|}{$\begin{array}{l}\text { Insufficient information about possibilities } \\
\text { for guidance and help following }\end{array}$} \\
\hline discharge from hospital & 19 & 49 & .01 \\
\hline \multicolumn{4}{|l|}{ Need for information about the disease } \\
\hline and treatment & 17 & 52 & .001 \\
\hline \multicolumn{4}{|c|}{$\begin{array}{l}\text { Need for information about how to solve } \\
\text { certain problems or where help might be }\end{array}$} \\
\hline found & 8 & 38 & .001 \\
\hline \multicolumn{4}{|c|}{ Contradictory information from different } \\
\hline care-professionals & 4 & 23 & .01 \\
\hline \multicolumn{4}{|l|}{ Less uncertain about } \\
\hline Which tests were to come & 19 & 42 & .01 \\
\hline The operation procedure & 19 & 40 & .05 \\
\hline \multicolumn{4}{|c|}{ The best way to stay or become physically } \\
\hline fit by exercise and/or diet & 38 & 59 & .05 \\
\hline
\end{tabular}

Table 4

Significant differences between trial and comparison groups on support and problem-experience variables

\begin{tabular}{lccc}
\hline & Trial $(\%)$ & Comparison $(\%)$ & $p\left(\chi^{2}\right)$ \\
\hline $\begin{array}{l}\text { Support } \\
\text { Support from social nurses/social workers } \\
\text { in coping with possible tension and }\end{array}$ & & & \\
$\quad$ other problems & 61 & 15 & .001 \\
Dissatisfaction with answers to questions & 6 & 27 & .01 \\
Problem-experience & & & \\
Fear & 21 & 49 & .01 \\
Anxiety & 21 & 47 & .01 \\
Depression & 29 & 43 & .01 \\
Tension & 33 & 100 & .001 \\
\hline
\end{tabular}


research. Fewer of the trial patients experienced tension, fear, anxiety and depression (see Table 4). No differences between the groups were found in the proportions reporting loneliness, insomnia, loss of control and threatened self-esteem.

\subsubsection{Other comments}

Both groups of patient made positive and negative comments on the information and care which they received. One disappointment with the use of the logbook in practice was the apparent lack of interest in its communication section on the part of careprofessionals. For example: 'I've a strong impression that neither the doctors nor the nursing staff were interested in the logbook. Even pushing them to fill it in at discharge didn't work. Though the speech therapist, physiotherapist and social nurse did fill it in.'

\section{Results}

\subsection{Care-professionals}

Evaluation questionnaires were returned by $54 \%$ $(n=59)$ of the professionals who provided care to patients in the trial group and agreed to participate in the study; and by $45 \%(n=35)$ of carers of comparison group patients. From Table 2, it is apparent that the response rates are dependent on the relatively small number of family doctors who returned the questionnaire.

\subsubsection{Use of the logbook}

Two-thirds of care-professionals in the trial situation had made reasonable use of the logbook. Only $16 \%$ indicated that they had never asked patients whether they had their logbook with them; and 32\% that they had never made a record of the medication which they had prescribed or terminated. The majority reported having read the communication forms in the logbook - especially, the general $(87 \%)$ and oncological (89\%) case-histories, and the patient's notes $(85 \%)$ and interchange forms $(81 \%)$.

As regards the information component of the logbook, $82 \%$ of care-professionals had handed over to patients the module concerning their responsibility for care and had explained it. Seventy-nine percent had read modules concerning other professionals' care.

In cases where they forgot to ask patients whether they had their logbook with them, this was mostly because they had not thought about it (58\%). Fiftytwo percent admitted that the patient sometimes gave them the logbook, without them subsequently filling in anything. Several professionals did not use the logbook because patients appeared to lack interest in it: 'Didn't ask patients if they had the logbook with them, because patient and partner had written very little in it.' 'On the few occasions on which patients produced their logbook, I had the feeling they were doing so for the physician or researcher who had given them the logbook, and not of their own volition.'

From the checklist, it was apparent that the majority of forms (97\%) contained the care-professional's particulars (name, address, contact numbers). The psychosocial profile was filled in most consistently $(90 \%)$, and the allergic reaction details the least (29\%). (Though it should be noted that if the patient had no allergic problems, the form only had to be filled in with a simple slash, which may have been overlooked.) The medication form was filled in in $59 \%$ of cases. But in $19 \%$ of the logbooks, care-professionals had forgotten to record the date of termination of medication.

The interchange form was used in $84 \%$ of the logbooks, giving a total of 557 entries - an average of seven per form (range: 1-37). One logbook contained 37 entries; seven contained only one. The majority of observations were recorded by speechtherapists or ENT-physicians (respectively, 116 in 34 logbooks, and 114 in 37 logbooks); followed by patients (49 in 12), family members (48 in 15) and physiotherapists (41 in 18). As far as primary carers are concerned, community nurses made 38 entries in nine logbooks and family doctors 22 in seven logbooks. The fewest entries were made by fellowsufferers (eight in just one logbook).

\subsubsection{Reaction to the logbook}

\subsubsection{Information}

Ninety percent of the care-professionals who had worked with the logbook agreed that it was a good means of improving the information given to pa- 
tients, and $79 \%$ believed that it made a considerable contribution to the continuity of information. Almost one-half $(46 \%)$ considered that it led to a decrease in the apparent provision of contradictory information.

Seventy-six percent agreed with the proposition that the logbook increased the level of patient-focussed treatment on the part of all professionals; and $47 \%$ considered that its use brought improvements to patient-care.

Around two-thirds of professionals found that the logbook gave them a rapid and comprehensive view of the patient's case-history, treatment procedure and psychosocial situation. Fifty percent were able themselves to take more account, in their care-activities, of a patient's problems and coping strategies.

\subsubsection{Contact with patients}

Around one-third of care-professionals found that the logbook made a considerable contribution to the ease with which a conversation with a patient could be initiated (35\%); and to the quality of the contact (32\%). None considered that it detracted from the spontaneity of contact with patients, or posed a threat to the contact. Two-thirds of professionals believed that patients were better informed than before the logbook had been used: they asked different and more focussed questions, and were able to be more assertive in their choice of method of treatment.

Forty-three percent considered that patients were more independent than was usually the case. The great majority denied that the logbook made patients more anxious $(90 \%)$ or misled them $(93 \%)$. They reported patients being more involved in their treatment $(92 \%)$, better prepared (93\%), and less dependent on the physician for information (57\%).

\subsubsection{Harmonising care-activities}

Sixty-three percent of the care-professionals who had worked with the logbook reported that it made a considerable contribution to their harmonising the care which they provided. Seventy-eight percent had read the modules of other professionals, and $67 \%$ found that the logbook helped them to keep abreast of what others were doing, and consequently to adjust their care-activities. Since using the logbook, more than one in four $(27 \%)$ knew better than previously to whom they should refer patients, and
(48\%) reported referring more patients than previously.

More than half of the care-professionals (56\%) considered that the logbook had made a considerable contribution to information exchange. Forty-one percent reported being better able, since using it, to reach other professionals in the context of caring for head-and-neck cancer patients; and more than one in four $(28 \%)$ reported an improvement in their contacts with fellow-professionals. Twenty-six percent had had colleagues draw their attention to the fact that their treatment did not conform to the relevant module in the logbook.

It was the view of four in five of the professionals that the logbook made a definite contribution to improving the fit of care in hospital to that at home. The transfer of patients to other care-professionals proceeded more smoothly (77\%). Nonetheless, $44 \%$ did note that they were dissatisfied with the way in which other professionals harmonised the information which they gave to patients.

\subsubsection{Suggestions for modifying the logbook}

Forty-two percent of care-professionals who used the logbook wished to see changes in its format. Suggestions touched, in particular, on its bulk (it measured $31 \times 27 \times 4.5 \mathrm{cms}$.). They advocated a smaller and more compact format, which would be handier and more convenient to use. It might have a soft, less conspicuous cover, without a logo. A number of care-professionals emphasised the value of the 'pull-out' version of the communication section. 'Patients often find that it is a rather large book to take with them. The pull-out folder is an improvement.'

Another suggestion was to add a readily accessible communication form, specifically for important messages, such as changes in treatment. The communication section was too extensive to peruse at every consultation.

Nearly one in four (23\%) of the care-professionals suggested changes in the content and layout of the logbook. The majority of the suggestions with regard to content referred to duplication of entries in the medical and nursing records by those in the logbook. For example: 'The communication-section is only meaningful for the professionals if they wish to write something in it - but I've no time for that in the 
out-patient clinic. I've scarcely enough time to keep the records up-to-date.' 'A module for nursing, in the form of a dossier. By this means the nursing staff will make more use of the logbook and have a higher degree of participation. As it is, they have to keep up-to-date with both the logbook and nursing records. This takes extra time.'

One professional wanted to substitute a medication 'passport', like that used by some dispensing chemists, for the medication form. Others wanted new forms to be added - such as a checklist for followup consultations, or sheets on which photographs could be stuck.

The principal suggestion for improving the layout of the logbook was to foreground the interchange form, so that care-professionals could not miss it.

One-half of the professionals had suggestions for keeping the logbook up-to-date. Importance was attached to keeping one's own module up-to-date and to regularly evaluating and supplementing the information which it offered.

\subsubsection{Comments from care-professionals in the comparison setting}

Comments made in the comparison setting made it clear that there is a need for a logbook: not everybody experienced the continuity of information as optimal.

Some nurses felt the need for a 'communicationform' and 'special help after the 'bad-news' consultation'. 'We don't always know what information the physician has given to the out-patient.' 'There is a regular breakdown in communication between the oncologist and nursing staff about the extent to which patients are informed about their situation. After a 'bad news" consultation, nursing staff have too little information to give effective help.'

Several family doctors signalled faults in communication with specialists. 'Reports from the specialist to the family doctor, even if they have to be provisional, arrive much too late.' 'Incidence is low. As family doctors, we have little experience in quickly spotting a tongue- or nasal-tumour. In the case of bleeding or pain, I do refer to the ENTphysician; but if it is malignant, there is already some progression.'

One physiotherapist in the comparison setting recognised that a patient might receive overlapping information from two or more sources. 'There's no formal system of transfer to or from physiotherapy. I don't know what information other professionals are giving. And so there's duplication.'

\section{Discussion}

From the results of the evaluation, it is apparent that use of the logbook by the trial patients led to their being better informed. They received more comprehensive and structured information, with less apparently contradictory material, as well as instruction on specific aspects of self-care.

It also contributed to a decrease in their psychosocial problems, such as tension, anxiety, fear, and feelings of depression. Even though they indicated that they had received more social support than did the comparison patients, no difference between the two groups was found for loneliness. An explanation for the latter finding might be drawn from House's [27] distinction between informative and emotional support. The logbook provided informative support. It is a lack ofemotional support which leads to loneliness.

Alongside information, instruction and guidance/ counselling, Dekkers [22] has also distinguished patient education. In this context, Bokma [23] has proposed an 'emancipation model' which highlights an increase in the patient's independence and responsibility for self. The majority of care-professionals in the trial setting noted that patients were relatively independent and better informed - a view which was not shared by their colleagues in the comparison setting. Trial patients asked different and more focussed questions, and they showed that they had read the logbook. This was echoed by the patients themselves: a majority reported that, because of the logbook, they had been able to ask more focussed questions.

However, they were not always able to exercise the intended independence and responsibility when it came to their offering the logbook to care-professionals. From the start of the study, it was clear that they too rarely did so; and as a result, intra-mural professionals had to be encouraged to ask for the lugbook themselves. (Each month, they received a list of patients who were participants in the logbook 
trial.) This worked much better. However, further research is needed to see whether such encouragement works in the long term; and to see how patients can be supported and counselled to become more independent in the doctor-patient relationship.

A majority of care-professionals believed that the logbook had contributed to the continuity of information; and reported having learned something about the care which others provided and having adjusted their care-activities accordingly. Despite the fact that the study's expectations as regards the harmonisation of care were fulfilled, the participation of family doctors was disappointing. It is not surprising that the majority of their questionnaires were not returned, given the response-rate in other studies. Family doctors feel themselves to be overwhelmed by paperwork. As one respondent put it: 'The average family doctor gets four or five requests a week to fill in questionnaires. Questionnaires are too long. They take up too much time.'

In the prescnt study, however, it was not just a matter of a questionnaire. All the family doctors were kept informed, both in writing (by means of a personal letter and a newsletter) and orally, about the purpose and progress of the study, and about their patient's particulars. Nevertheless, their involvement in the study was lower than expected. They had made entries on forms in only seven of the 70 logbooks. And this despite the fact that 33 patients reported that they had offered the logbook to their family doctor. This may be a reason why no more trial patients said that they had received support from their family doctor than did comparison patients even though more patients in the present study reported receiving such support than did those in an earlier study of head-and-neck cancer patients [2]. Improving collaboration between specialists and family doctors remains a challenge.

Not all communication forms were used optimally. Those which were most fully completed were those for 'patient details' and the psychosocial profile. This was not unexpected, because these data were recorded by the social nurse, who received all the trial patients after their 'bad news' consultation. Nevertheless, these forms were not as often read as were the 'patient-details' and the interchange form. Although the psychosocial profile was well completed, it was least often read by the care-professionals. The reason given for this omission was 'lack of time'.
The forms which patients least often used were the glossary and the list of other information-sources. They were rarely or never referred to. It can be questioned whether they should remain as standard components of the logbook. They might instead be given on request, if a patient indicates a need for them. However, it is also possible that patients might refer to them at a later point in time, beyond that covered by the present evaluation.

Following the pilot study, the communication section was made detachable from the rest of the logbook, by means of a pull-out folder, to make it more convenient for taking to consultations. This appeared to be a success.

Despite the logbook having fulfilled the expectations set for it, the care-professionals made a number of comments which indicated that its form, content and layout could be improved. They argued for a smaller format than A4; a soft cover, without a logo on the front; and a separation of the communication and information sections into two folders.

There was no comment on the ring-binding. A loose-leaf binder is essential if the information section is to contain both standard modules and modules which are specific to a particular patient category. The alternative would be to produce a distinct information booklet for each category of patient - though the logbook would then not be so readily open to supplementation or up-dating. Moreover, it would no longer be personalised; and all its contents would be given at once. A countervailing advantage would be that every patient would be guaranteed to have all the modules on time.

Other suggestions were to replace the medication form by the 'medicine passport' which many dispensing chemists now use; and to place the communication form in a prominent position at the front of the logbook, so that users would not have to search for it.

It is interesting that most of the comments on the communication form came from (excluding the ENT-physicians, who had initiated the study) the speech-therapist and physiotherapist. This is not surprising, since paramedics do not write in medical dossiers - it did not involve double work for them. On the contrary, it was a new experience for paramedics to be able to communicate in this way with other care-professionals; and apparently it was a success. 


\section{Conclusion}

The results of this evaluation study suggest that patients who had been given the logbook had more information, and information which was clearer and less contradictory, than did patients without the logbook. The former group of patients was better prepared for the possibilities for care following discharge, and felt less uncertain about a number of matters. The loghook helped them experience a sense of support when feeling 'down'; and directed them to the appropriate person for answers to any questions or problems which they had. The support of the social nurse (logbook co-ordinator) was particularly valued. Such support was not available to patients in the comparison group.

The logbook also gave patients a better grasp of their situation. This was apparent from their relatively infrequent experience of anxiety, fear, depression and tension. It was also apparent in the questions which they asked: according to the care-professionals they asked more questions, and questions of a different type from those of other patients. Logbook patients appeared themselves to be more satisfied with the answers to their questions which they received. Most of the care-professionals found that the logbook helped patients to be better prepared for, and more involved in, their care, and less dependent on the physician for information.

The harmonisation of care between care-professionals also appears to have been improved somewhat by the logbook. They reported that, because of the logbook, they were more aware of the careactivities of others and could more adequately adjust their own to meet them. Moreover, the majority found that it had enabled them to gain a more rapid and complete view of the patient's case-history, treatment, and psychosocial situation. In the case of half of the care-professionals, the logbook contributed to an effective exchange of information and to their being able to take account of the patient's problems and coping-strategies. Contact with colleagues was improved for one in four of them.

It can be concluded that the logbook has a contribution to make to the improvement of continuity of information for patients with a head-and-neck tumour. However, in order to make optimal use of the logbook, changes are necessary in: (i) its form and content; (ii) the attitudes of care-professionals, so that they are more willing to read, and write in, the logbook; and (iii) the attitudes of patients, so that they shift from 'waiting for the instruction of care professionals' to 'taking initiative and joint responsibility themselves'.

\section{Acknowledgments}

The study reported here was supported by a grant from the Dutch Committee for the Chronically III (Nationale Commissie voor Chronisch Zieken).

\section{References}

[1] Wouterlood-van Cleef IE, Boer MF de, Molendijk LW, Jong PC de, Knegt PP, Pruyn JFA and Visch LL. Nazorg . . . hoofd of halszaak? Een onderzoek naar knelpunten die hulpverleners ervaren bij de nazorg voor patienten die behandeld zijn voor hoofd-halstumor in de regio van het IKR. (Grappling with after-care: a study of the constraints experienced by care-professionals in the after-care of patients being treated for head-and-neck cancer in the Rotterdam region). Rotterdam: Integraal Kankercentrum, 1989.

[2] Boer MF de, Pruyn JFA and Bosman B. Frequentie overzicht KNO-longitudinaal. (Longitudinal summary of ENT-frequencies). Internal publication. Rotterdam: Dr. Daniel den Hoed Clinic, 1989.

[3] Boer MF de, Pruyn JFA, Borne B. van den, Knegt PP, Ryckman RM and Verwoerd CDA. Rehabilitation outcomes of long-term survivors for head and neck cancer. Head and Neck 1995; Nov/Dec: 503-515.

[4] Bjordal K, Freng A, Thorvik J, Kaasa S. Patient self-reported and clinician-rated quality of life in head and neck cancer patients: a cross-sectional study. Oral Oncol, Eur J Cancer 1995;31B:235-41

[5] Pruyn JFA, Jong PC de, Bosman LJ, Poppel JW van, Borne HW van den, Ryckman RM and Meij K de. Psychosocial aspects of head and neck cancer: a review of the literature. Clin. Otolaryngol. 1986;11:469-474.

[6] Fallowfield LJ, Hall A, Maguire GP, Baum M. Psychological outcomes of different treatment policies in women with early breast cancer outside a clinical trial. Brit Med J 1990;301:575-80.

[7] Fallowfield LJ. Giving sad and bad news. Lancet 1993; $341: 476-8$.

[8] Fallowfield LJ, Ford S, Lewis S. Can oncologists detect distress in the outpatients and how satisfied are they with their performance during bad news consultations?. Brit J Cancer 1994;70:767-70.

[9] Ngan YS, Tang GW. Needs and emotional states in cancer patients: a study of 21 Chinese women with carcinoma of the ovary. J Psychosom Obstet Gynaecol 1984;3:223-31.

[10] Morrow JR, Hoagland AC, Carpenter PJ. Improving physi- 
cian-patient communications in cancer treatment. J Psychosoc Oncol 1983;1:93-101.

[11] Cassileth BR, Zupkis KV, Sutton-Smith K, March V. Information and participation preferences among cancer patients. Ann Int Med 1980;92:832-6.

[12] Cuisinier MCJ, van Eijk JTM, Jonkers R, Dokter HJ. Psychosocial care and education of the cancer patient: strengthening the physician's role. Patient Educ Couns 1986;8:5-16.

[13] Grahn G, Johnson J. Learning to cope and living with cancer. Scand J Caring Sci 1990;4:173-81.

[14] Rimer B. Keintz MK. Glassman B. Cancer patient education: reality and potential. Prev Med 1985;14:801-18.

[15] Brody DS, Miller SM, Lerman CE. The relationship between patients' satisfaction with their physicians and perceptions about interventions they desired and received. Med Care 1989;27:1027-35.

[16] Greenfield S, Kaplan S, Ware JE. Expanding patient involvement in care: Effects on patients' outcomes. Ann Int Med 1985;102:520-8.

[17] Conkling VK. Continuity of care issues for cancer patients and families. Cancer 1989;64:290-4.

[18] Wouden JC van der. Samenwerking tussen huisartsen en specialisten bij mensen die lijden aan kanker: verslag van de eerste onderzoeksfase. (Collaboration hetween family-doctors and specialists in the care of patients suffering from cancer: report of the first phase of research). Rotterdam: Rotterdams Universitair Huisartsen Instituut, 1985.

[19] Visser APh, Menko FA. Samenwerking tussen echelons bij de zorg voor patienten met kanker. (Vertical collaboration in the care of cancer patients). Medisch Contact 1987;39:123942.

[20] Horst FG van der, Witte L de, Philipsen $H$ and Joosten $J$. Afstemming van de zorg voor en voorlichting aan patienten met chronische aandoeningen in de thuissituatie. (Adjustment of care and information in the home-situation for patients with chronic disorders). In: Cuisenier M, van Eijk J, Grol R and Jonkers $\mathrm{R}$ eds. Patientvoorlichting in de eerste lijn. Uitgeverij voor Gezondheidsbevordering, 1989.

[21] Courtens AM, Crebolder H. Continuiteit van de zorgverlening bij patienten met kanker. (Continuity in the provision of care for cancer patients). IKR-bulletin 1992;16:15-9.

[22] Dekkers F. Patientenvoorlichting: de onmacht en de pijn. (Information for patients: powerlessness and pain). Baarn: Ambo, 1981.

[23] Bokma J, Patientenvoorlichting: kiezen in vierstromenland. (Information for patients: choices at the crossroad). Het Ziekenhuis 1984;18:750-3.

[24] Roberts CS, Cox CE, Reintgen DS, Baile WF, Gibertini M. Influence of physician communication on newly diagnosed breast patients' psychological adjustment and decision-making. Cancer 1994;74:336-41.

[25] Pruyn JFA. Coping with stress in cancer patients. Patient Educ Couns 1983;5:57-62.

[26] Wersch A van, Boer MF de and Pruyn JFA. Verbetering van continuiteit van voorlichting aan patienten die behandeld worden voor een tumor in het hoofd-hals gebied door coordinatie en het gebruik van een logboek. (Improvement in the continuity of information for patients being treated for a head-and-neck tumour, by means of coordination and the use of a lnghook). Report to the National Commission for the Chronically Ill. Willemstad: IGO, 1992.

[27] House JS, Landis KR, Lumberson D. Social relationships and health. Science, 1988;241:540-5.

[28] Borne HW van den and Pruyn JFA. Lotgenotencontact bij kankerpatiënten. Dissertatie. (Cancer-patients' contact with fellow-sufferers. PhD thesis). Assen/Maastricht: Van Gorcum, 1985.

[29] Borne H van den, Pruyn J and Hcuvel WJA van den. Effects of contacts between cancer patients on their psychosocial problems. Patient Educ. Couns. 1987;9:33-38. 